\title{
The intrinsic subtalar ligaments have a consistent presence, location and morphology
}

\author{
Frederick Michels ${ }^{\mathrm{a}, \mathrm{b}, *}$, Giovanni Matricali $^{\mathrm{c}, \mathrm{d}, \mathrm{e}}$, Evie Vereecke ${ }^{\mathrm{f}}$, Miloud Dewilde $^{\mathrm{f}}$, \\ Frederik Vanrietvelde ${ }^{g}$, Filip Stockmans ${ }^{\mathrm{a}, \mathrm{f}}$ \\ a Orthopaedic Department, AZ Groeninge, President Kennedylaan 4, 8500 Kortrijk, Belgium \\ ${ }^{\mathrm{b}}$ GRECMIP - MIFAS (Groupe de Recherche et d'Etude en Chirurgie Mini-Invasive du Pied - Minimally Invasive Foot and Ankle Society), Merignac, France \\ ${ }^{\mathrm{c}}$ Department of Development and Regeneration, KU Leuven, Leuven, Belgium \\ d Department of Orthopaedics, Foot and Ankle Unit, University Hospitals Leuven, KU Leuven, Leuven, Belgium \\ e Institute of Orthopaedic Research and Training, KU Leuven, Leuven, Belgium \\ ${ }^{\mathrm{f}}$ Dept. Development and Regeneration, Faculty of Medicine, University of Leuven Campus Kortrijk, Etienne Sabbelaan 53, 8500 Kortrijk, Belgium \\ ${ }^{\mathrm{g}}$ Radiology Department, AZ Groeninge Kortrijk, President Kennedylaan 4, 8500 Kortrijk, Belgium
}

\section{A R T I C L E I N F O}

\section{Article history:}

Received 3 November 2019

Received in revised form 1 February 2020

Accepted 2 March 2020

Available online $\mathrm{xxx}$

\section{Keywords:}

Hindfoot instability

Subtalar ligament

Ligament reconstruction

Interosseous talocalcaneal ligament

Anterior capsular ligament

Cervical ligament

\begin{abstract}
A B S T R A C T
Background: Chronic subtalar instability is a disabling complication after acute ankle sprains. Currently, the literature describing the anatomy of the intrinsic subtalar ligaments is limited and equivocal which causes difficulties in diagnosis and treatment of subtalar instability. The purpose of this study is to assess the anatomical characteristics of the subtalar ligaments and to clarify some points of confusion.

Methods: In 16 cadaveric feet, the dimensions and locations of the subtalar ankle ligaments were assessed and measured. CT-scans before dissection and after indication of the footprints with radio-opaque paint allowed to generate 3D models and assess the footprint characteristics.

Results: The cervical ligament $(\mathrm{CL})$ had similar dimensions as the lateral ligaments: anterior length $13.9 \pm$ $1.5 \mathrm{~mm}$, posterior length $18.5 \pm 2.9 \mathrm{~mm}$, talar width $13.6 \pm 2.2 \mathrm{~mm}$, calcaneal width $15.8 \pm 3.7 \mathrm{~mm}$. The anterior capsular ligament (ACaL) and interosseous talocalcaneal ligament (ITCL) were found to be smaller structures with consistent dimensions and locations.

Conclusion: This study identified consistent characteristics of the intrinsic subtalar ligaments and clarifies the local anatomical situation. The dimensions and footprints of the intrinsic ligaments of the subtalar joint suggest a more important role of the CL and ACaL in the stability of the subtalar joint. The results of this study are relevant to improve diagnostic tools and offer some guidelines when reconstructing the injured ligaments.
\end{abstract}

(c) 2020 European Foot and Ankle Society. Published by Elsevier Ltd. All rights reserved.

\section{Introduction}

Chronic lateral hindfoot instability is a common complication of an ankle sprain. Anatomically, two forms of ligamentous instability can be distinguished: ankle instability and subtalar instability [1]. Ankle instability has been well documented in the literature and experts agree on several aspects of diagnosis and treatment [2]. Anatomical reconstruction of the anterior talofibular ligament (ATFL) and calcaneofibular ligament (CFL) has been extensively described $[3,4]$.

In contrast to ankle instability, literature addressing subtalar instability is rather limited. The diagnosis is still difficult, which

\footnotetext{
* Corresponding author at: Orthopaedic Department, AZ Groeninge, President Kennedylaan 4, 8500 Kortrijk, Belgium.

E-mail address: frederick.michels@azgroeninge.be (F. Michels).
}

compounds adequate treatment [2,5-7]. Subtalar instability has been related to injuries of different ligaments: the calcaneofibular ligament $(\mathrm{CFL})$, the cervical ligament $(\mathrm{CL})$, the anterior capsular ligament $(\mathrm{ACaL})$, and the interosseous talocalcaneal ligament (ITCL) [7-9]. The CFL, the only ligament bridging both the tibiotalar and subtalar joint, has an important function in the stability of the subtalar joint [10,11]. The other ligaments, called the intrinsic subtalar ligaments, also seem to play an important role to stabilize the subtalar joint, but literature about their anatomy is equivocal [12-17]. Today, the contribution of each ligamentous structure in the stability of the subtalar joint is still unclear [7,15].

The purpose of this study is to assess the anatomical characteristics of the subtalar ligaments and to clarify some points of confusion. To this end, we performed a cadaveric study to quantify the dimensions and footprints of the intrinsic subtalar ligaments (ITCL, CL, ACaL and the tarsal canal ligament (TCL)) in comparison with the dimensions of the ATFL and CFL in the same 
specimens. 3D-models were generated to visualize the ligament and footprint position.

\section{Materials and methods}

Sixteen paired fresh frozen cadaveric feet ( 2 female and 6 male) with a mean age of 80.2 years (range, 72-86) were obtained from the Human Body Donation Programme of the university. Approval of the ethical advisory board was obtained to use the specimens. None of the specimens had visible signs of surgery or musculoskeletal disorders at the level of the foot.

\subsection{Dissection technique and measurements}

Dissection was performed to assess the ligament presence, location, morphology and dimensions. Ligament dimensions were measured using a digital calliper accurate to $0.01 \mathrm{~mm}$ and were taken by one investigator to decrease the possibility of interobserver variability. Each measurement was performed three times, interrupted by other measurements and dissections to avoid bias by the earlier results. For each parameter, the mean value was used. During all measurements, the talocrural and subtalar joints were placed in neutral position without any force that would elongate the ligaments. Foot length was measured to assess the average foot size.

The superficial soft tissues, the extensor digitorum brevis, the inferior extensor retinaculum and the peroneal tendons were removed to expose the footprints of the CL, ATFL and CFL. The dimensions of the ATFL and CFL were measured at different points. The behaviour of the $\mathrm{CL}$ was assessed during a passive movements of the subtalar joint.

Next, the surrounding structures were removed from the calcaneus and talus. The distances from the CL footprints to the cartilage of the talonavicular joint and the calcaneocuboid joint, were measured.

The lateral capsule of the posterior facet was removed from posterior to anterior to allow visualisation of the ACaL. An osteotomy of the talar body was performed in the frontal plane to allow assessment of the ACaL and visualisation of the deeper structures. The talar body was gradually removed from posterior to anterior until visualisation of the structures in the tarsal canal. The ligamentous structure on the anterior border of the posterior facet was defined as the ACaL. After assessment of the ACaL and CL, both ligaments were cut to allow good visualisation and assessment of the ITCL. Next, the ITCL was cut to assess the remaining ligamentous structures anterior to the ITCL, defined as the tarsal canal ligament. Calcaneus and talus were separated and exposed during $24 \mathrm{~h}$ to allow drying. Subsequently, the footprints were marked with radio-opaque paint (Magnetic paint, DecoMode, Maxeda DIY Group).

\subsection{CT scanning protocol and image processing}

Spiral CT-scan images (mA V 101, KV 100, voxel size 0.625 , slice thickness 0.625) were obtained of all the specimens. A first scan was performed of the intact cadaveric foot before dissection. A second scan was performed of talus and calcaneus after footprint marking.

The CT-scan data were segmented manually using Mimics Research 19.0 (Materialise NV, Leuven, Belgium) to create a virtual 3D bone model of the foot (Fig. 1). The radio-opaque paint allowed manual segmentation of the ligament footprints. The size of the footprints was measured on the 3D models and the position was assessed in relation to osseous landmarks. To minimize the error during the different steps in the 3D image processing all steps were performed independently by two researchers and several osseous landmarks were indicated (Fig. 2). The lateral border of the middle calcaneal articular surface of the talar neck was used to make a distinction between the sinus tarsi and the tarsal canal [13].

Before measurement, the 3D models were compared with the original specimens to ensure correct delineation of the footprint area. The 3D models with visualised footprints were registered on the 3D models derived from the CT scans before dissection. Combination with the data from the dissections allowed us to generate $3 \mathrm{D}$ models of the ligaments.

\subsection{Statistical methods}

For each ligament, mean values and standard deviation of each dimension (length, width and thickness) were calculated. All data was checked for normality using the Shapiro-Wilk's test ( $p>0.05$ ) and each dimension had a normal distribution. An analysis of variance (ANOVA) was used to evaluate the effect of ligament type and individual on each dimension. A Tukey's Honest Significance Difference method was used to perform two-by-two comparisons between ligaments. All statistical analyses were performed using R Core Team, version 3.5.1 (Foundation for Statistical computing, Vienna, Austria).

\section{Results}

The average foot length was $249.7 \pm 25.8 \mathrm{~mm}$. Table 1 lists the dimensions of the different ligaments. The ATFL was significantly shorter and broader than the CFL, but both ligaments had a similar thickness (Table 2).

\subsection{Cervical ligament}

In all cases, the CL was consistently present, most commonly as a broad bundle of fibers with a striated appearance. Several types were distinguished: single bundle $(2 / 16)$, double bundle $(5 / 16)$, multiple bundle (9/16). The CL was the broadest of all measured ligaments and longer than the ATFL and ITCL.

Both footprints of the CL were always located in the sinus tarsi (Fig. 2). The talar footprint was irregularly round to oval shaped with average length of $12.7 \pm 2.1 \mathrm{~mm}$, and width of $7.7 \pm$ $2.4 \mathrm{~mm}$. This footprint started anteriorly, at a mean distance of $3.3 \pm 0.8 \mathrm{~mm}$ from the cartilage of the talonavicular joint, on the level of the lower third of the talar neck, to the most medial point of the lateral side on the talar neck. The talar footprint was located in the extension of the anterior border of the tarsal canal. Because of its irregular shape an axis could not be determined.

The calcaneal footprint had an irregular oval shape with an average length of $14.5 \pm 3.3 \mathrm{~mm}$ and width of $6.5 \pm 1.7 \mathrm{~mm}$. The footprint started on the anterior lateral superior surface of the calcaneus (anterior calcaneal tubercle) in all specimens. The anterior border was located at a mean distance of $4.8 \pm 1.1 \mathrm{~mm}$ from the cartilage of the calcaneocuboid joint. The average axis of the calcaneal footprint formed an angle of $3.1 \pm 19.3^{\circ}$ to the longitudinal axis of the calcaneus in the axial plane and ran from proximal medial to distal lateral.

The ITCL and the posterior part of the CL ran in succession of each other with an aspect of a curtain. In eight specimens, a superiorly located ligamentous connection was found between both. This connection was tensioned during inversion.

In neutral position, the CL ran from talus anterior superior medial to calcaneus posterior inferior lateral. When holding the foot in an inverted position, the CL became tensioned into a vertical position. When holding the foot in an everted position, the CL came into a horizontal position with moderate tension. Anterior drawer in neutral position tensioned the CL. This was in contrast to the CFL 
a Inferior view talus

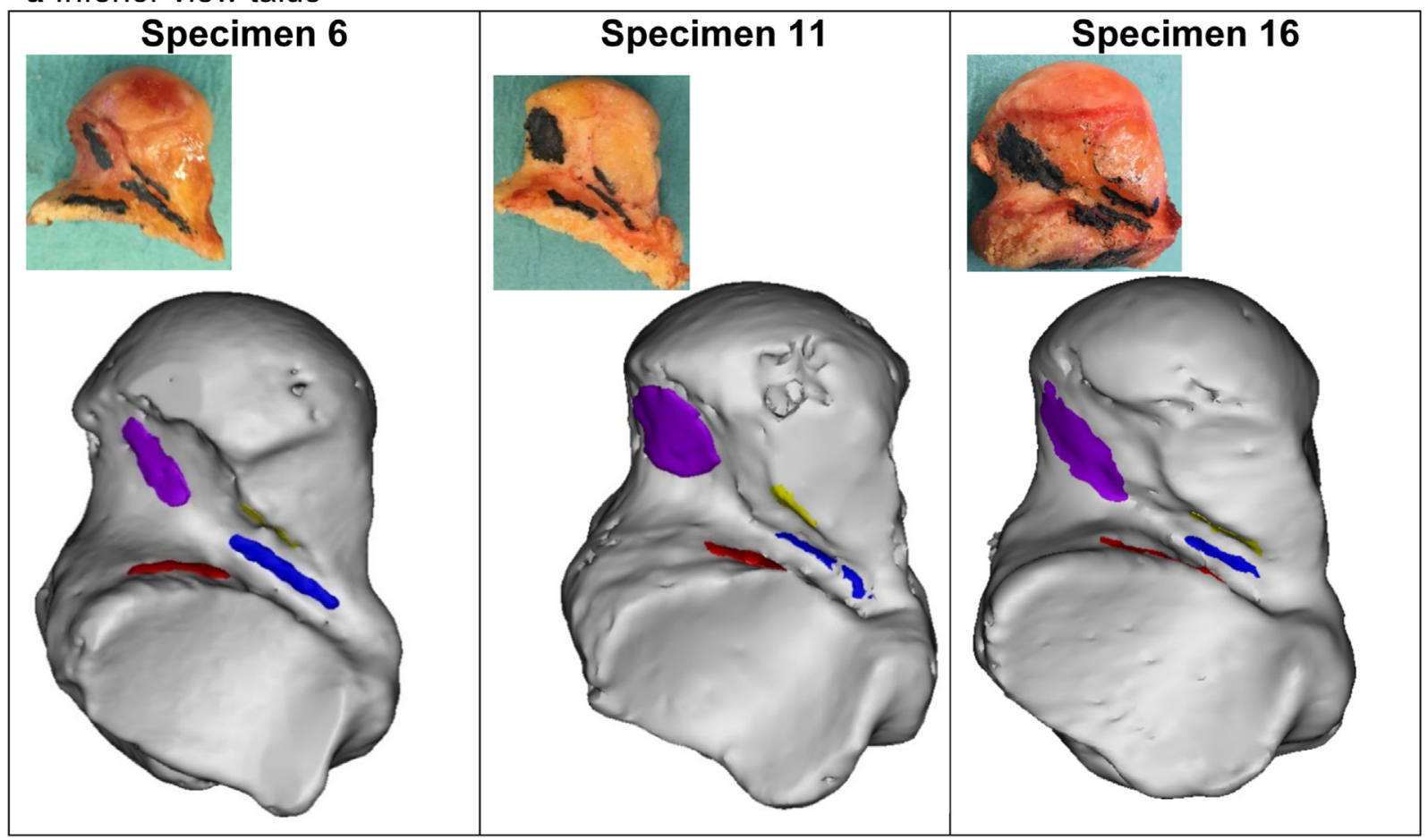

b Superior view calcaneus
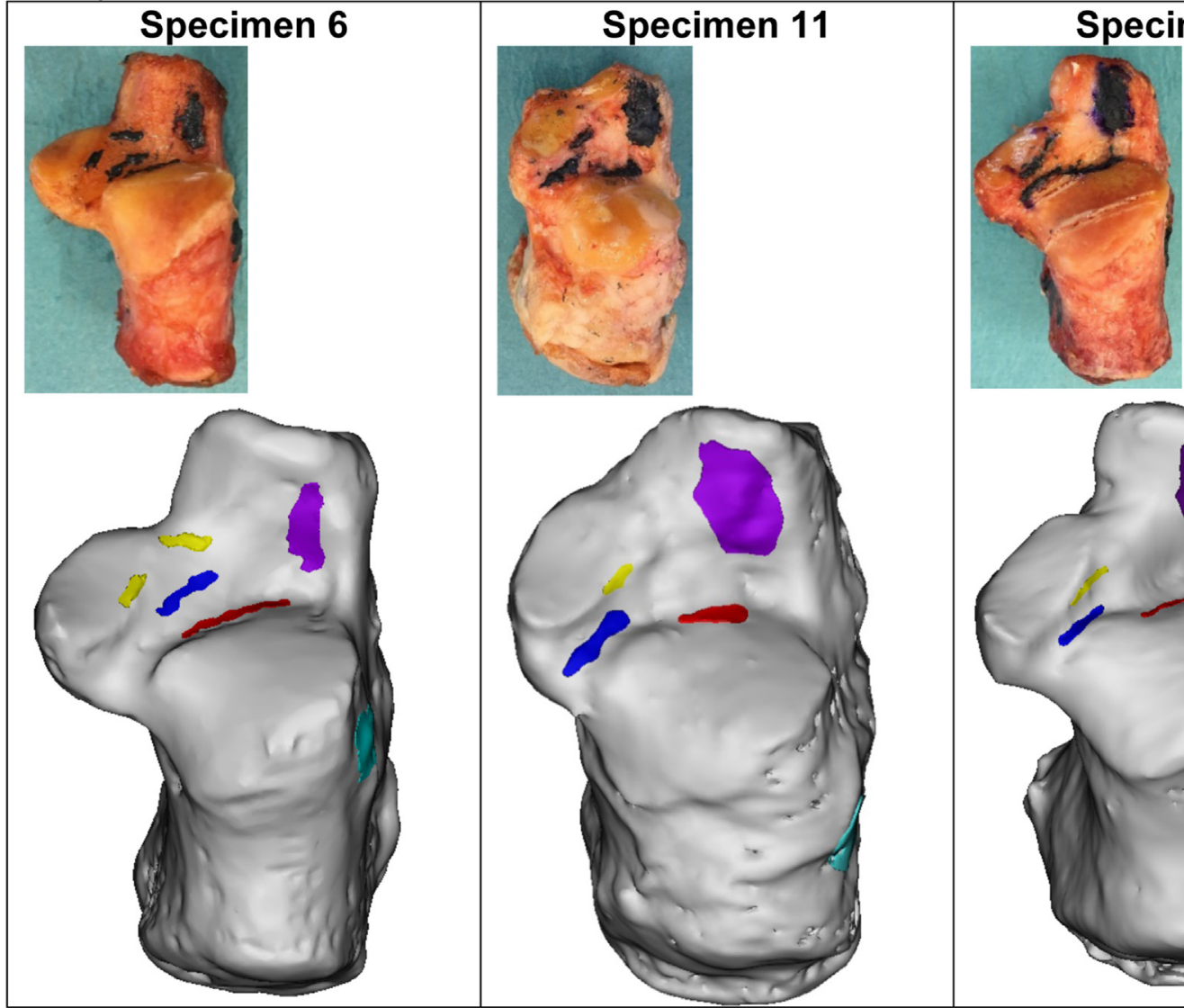

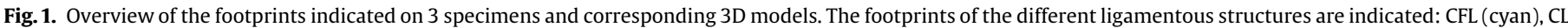

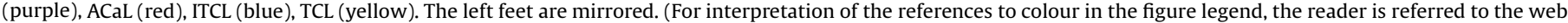
version of this article.) 

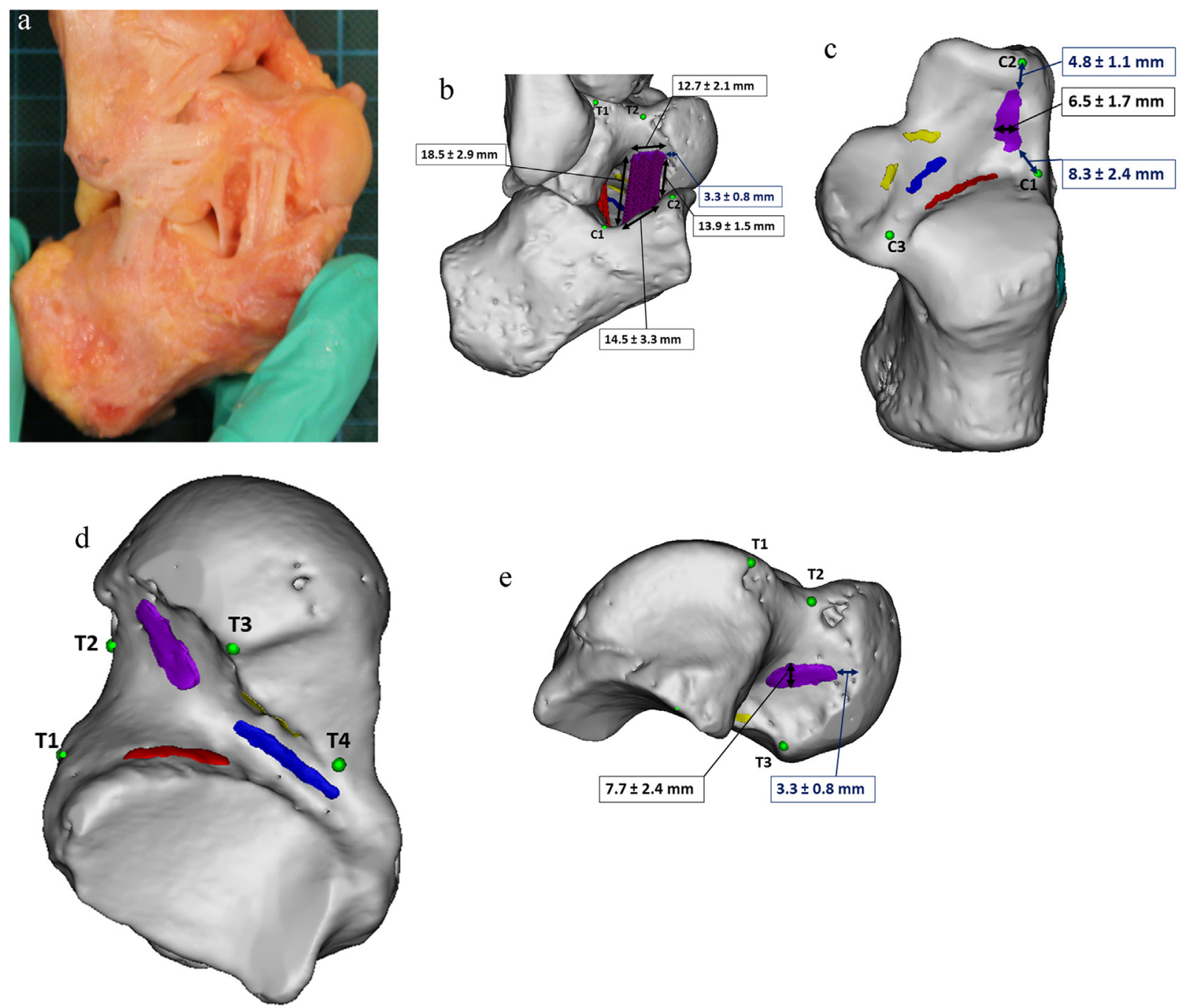

f

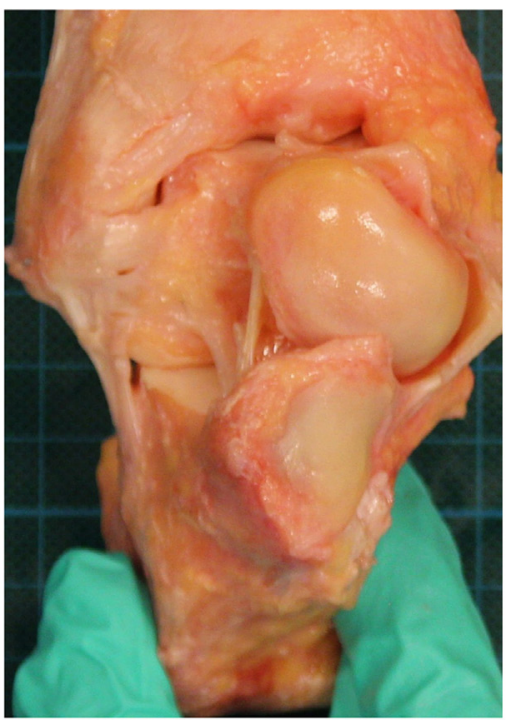

$\mathrm{g}$

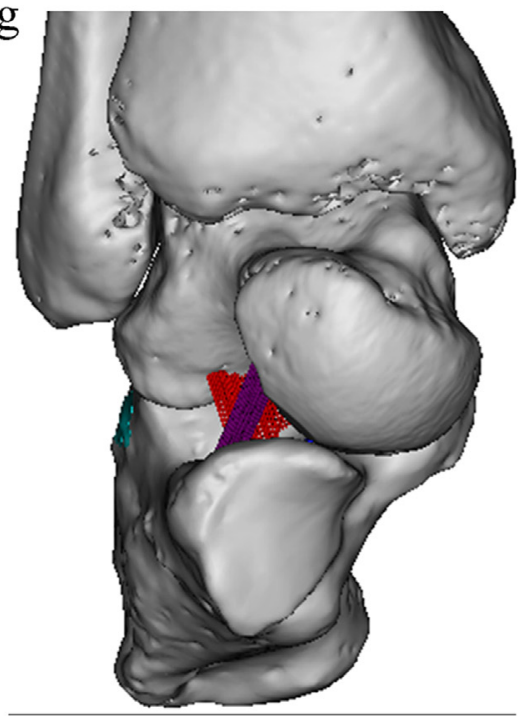

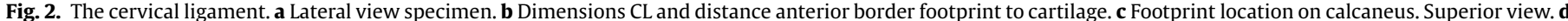
Footprint location on talus. Inferior view. e Footprint location on talus. Lateral view. $\mathbf{f}$ Anterior view specimen. $\mathbf{g}$ Anterior view $3 \mathrm{D}$.

The different osseous landmarks and footprints indicated on talus and calcaneus.

The footprints are indicated: CL (purple), ACaL (red), ITCL (blue), TCL (yellow).

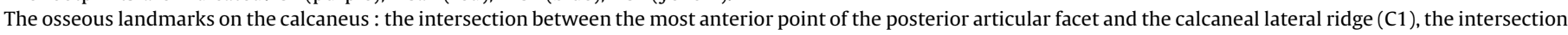

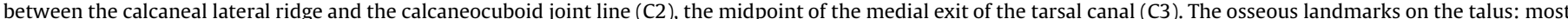

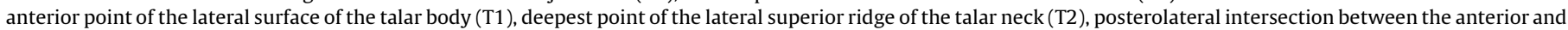

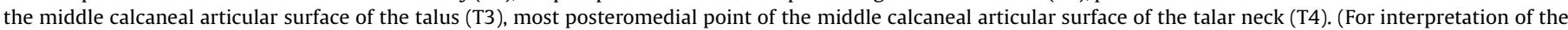
references to colour in the figure legend, the reader is referred to the web version of this article.)

Please cite this article in press as: F. Michels, et al., The intrinsic subtalar ligaments have a consistent presence, location and morphology, Foot Ankle Surg (2020), https://doi.org/10.1016/j.fas.2020.03.002 
Table 1

Overview of ligament dimensions (mm). Values are mean values $\pm \mathrm{SD}$.

\begin{tabular}{|c|c|c|c|c|c|c|c|c|}
\hline & ATFL & & CFL & & $\mathrm{CL}$ & & ITCL & \\
\hline \multirow[t]{4}{*}{ Ligament length } & Superior & $14.8 \pm 1.8$ & Anterior & $24.7 \pm 2,2$ & Anterior & $14.0 \pm 1.5$ & Lateral & $9.1 \pm 2.0$ \\
\hline & Inferior & $11.7 \pm 1.4$ & Posterior & $23.8 \pm 2.5$ & Posterior & $18.5 \pm 2.9$ & Medial & $7.5 \pm 1.7$ \\
\hline & Centre & $13.1 \pm 1.7$ & Centre & $25.4 \pm 3.0$ & Centre & $17.3 \pm 2.3$ & & \\
\hline & Mean & $13.2 \pm 1.5$ & Mean & $24.6 \pm 2.3$ & Mean & $16.6 \pm 1.8$ & Mean & $8.3 \pm 1.6$ \\
\hline \multirow[t]{4}{*}{ Ligament width } & Fibular footprint & $11.4 \pm 2.4$ & Fibular footprint & $6.8 \pm 1.4$ & Talar footprint & $13.6 \pm 2.2$ & Talar footprint & $13.3 \pm 4.7$ \\
\hline & Talar footprint & $13.4 \pm 2.4$ & Calcaneal footprint & $8.6 \pm 2.2$ & Calcaneal footprint & $15.8 \pm 3.7$ & Calcaneal footprint & $10.1 \pm 2.3$ \\
\hline & Centre & $10.4 \pm 2.0$ & Centre & $6.0 \pm 1.9$ & & & & \\
\hline & Mean & $11.8 \pm 2.0$ & Mean & $7.2 \pm 1.5$ & Mean & $14.7 \pm 2.4$ & Mean & $11.7 \pm 3.3$ \\
\hline \multirow[t]{4}{*}{ Ligament thickness } & Centre & $1.4 \pm 0.2$ & Centre & $1.5 \pm 0.4$ & Centre & $1.7 \pm 0.7$ & Centre & $1.1 \pm 0.5$ \\
\hline & Talar footprint & $1.6 \pm 0.4$ & Fibular footprint & $1.9 \pm 0.6$ & Talar footprint & $1.9 \pm 0.7$ & & \\
\hline & Fibular footprint & $1.7 \pm 0.4$ & Calcaneal footprint & $1.6 \pm 0.5$ & Calcaneal footprint & $2.1 \pm 0.9$ & & \\
\hline & Mean & $1.6 \pm 0.3$ & Mean & $11.7 \pm 1.4$ & Mean & $1.9 \pm 0.7$ & & \\
\hline
\end{tabular}

Table 2

Results ( $p$ values) of paired t test comparing the different ligament dimensions.

\begin{tabular}{llll}
\hline \multicolumn{1}{c}{ ATFL } & CFL & CL & ITCL \\
\hline Ligament length & & & \\
ATFL & $<0.0001$ & $<0.0001$ & $<0.0001$ \\
CFL & & $<0.0001$ & $<0.0001$ \\
CL & & & $<0.0001$ \\
ITCL & & & \\
Ligament width & & & \\
ATFL & $<0.0001$ & $<0.01$ & n.s. \\
CFL & & $<0.0001$ & $<0.0001$ \\
CL & & & $<0.01$ \\
ITCL & & & \\
Ligament thickness & & n.s. & $<0.01$ \\
ATFL & n.s. & n.s. & $<0.005$ \\
CFL & & & $<0.0001$ \\
CL & & & \\
ITCL & & &
\end{tabular}

n.s.: non-significant.

which was not tensioned during anterior drawer and everted position.

\subsection{Interosseous talocalcaneal ligament}

The ITCL was consistent in presence and dimensions (Table 2) (Fig. 3). The ITCL was significantly thinner and shorter than the other ligaments (ATLF, CFL and CL). Several morphological variations of the ITCL were observed: band type (11/16), fan type $(1 / 16)$, and multiple type (4/16). The talar footprint consisted of two parts in nine specimens (9/16).These characteristics resulted in a longer footprint on the talus compared to the calcaneus: the talar footprint measured $10.9 \pm 2.7 \mathrm{~mm}$, while the calcaneal footprint measured $9.5 \pm 3.5 \mathrm{~mm}$. Both footprints had a linear shape and were always located in the superior and inferior part of the tarsal canal. The axis of both footprints ran parallel with the tarsal canal.

\subsection{Anterior capsular ligament}

The ACaL was present in 15 of the 16 feet. The ACaL was a rectangle band in all specimens and corresponded to a thickened part of the anterior joint capsule of the posterior facet. In four paired, the ACaL consisted of two parallel bands. The lateral length was $11.4 \pm 1.0 \mathrm{~mm}$, the medial length was $6.9 \pm 1.0 \mathrm{~mm}$. The band could easily be recognized from a lateral view into the sinus tarsi and from an intra-articular point of view (Fig. 4). The ACaL was tensioned when the foot came in an inverted position and during anterior drawer of the calcaneus. The footprints of the ACaL were located in the sinus tarsi but often continued inside the tarsal canal. The calcaneal footprint of the ACaL was linear with an average length of $10.8 \pm 2.7 \mathrm{~mm}$. The footprint was located on the anterior edge of the posterior articular facet and ran parallel to it. The footprint position showed some variation in the coronal plane. The lateral edge of the footprint was located at $12.3 \pm 4.5 \mathrm{~mm}$ from landmark $\mathrm{C} 1$. The centre of the calcaneal footprint was located at $55.0 \pm 13.3 \%$ (ranging from 39.1 to $80.2 \%$ ) from landmark $\mathrm{C} 1$.

The talar footprint of the ACaL was linear with an average length of $10.0 \pm 2.7 \mathrm{~mm}$. The footprint was located in the posterior part of the sinus tarsi but was more distant from the articular facet. The lateral edge was located at $6.0 \pm 1.3 \mathrm{~mm}$ and the medial edge at 3.1 $\pm 1.4 \mathrm{~mm}$ from the articular facet.

\subsection{Tarsal canal ligament}

The footprints of the TCL were always located in the tarsal canal. After cutting the ITCL, a more anteriorly located ligamentous structure was found in 14 specimens: some fibers (4 feet) or a separated ligamentous structure (10 feet). Different types could be distinguished: band-type (5), V-type (3), and inverted V-type (2). Length variated from 6 to $11 \mathrm{~mm}$, maximal ligament width was 6 $\mathrm{mm}$. Thickness was not measurable.

\section{Discussion}

The literature about the anatomy of the subtalar ligaments is equivocal [12,13,15-17]. First, there is some confusion about the terminology of the different ligaments, as summarized in Table 3. Second, the ACaL is often considered as the ITCL $[18,19]$. Third, footprints are often indicated by schematic figures not based on measurements [18,20-24].

Besides the anatomy, there is still discussion regarding the function of the different ligaments in the stability of the subtalar joint $[14,15]$. The CFL is assumed to be an important stabilizer of both joints $[10,11]$. However, the contribution of the intrinsic ligaments to subtalar stability is still a matter of debate. Some investigators consider the ITCL as the second most important stabilizer $[9,10,25]$, while others believe that the $\mathrm{CL}[26,27]$ is more important for subtalar instability. This disagreement may be partially explained by the confusion about the anatomy.

The detailed information about the dimensions of the different intrinsic subtalar ligaments in this study allow to clarify some of this confusion. As the dimensions of the ATFL and CFL in this study correspond with earlier literature, they can be used as a reference [3]. Below, we compare our findings of the intrinsic subtalar ligaments to the information in literature (Table 4).

This study demonstrated the CL to have similar dimensions as the ATFL and CFL. Moreover, the dimensions of the footprints that were quantified in this study are much larger than the dimensions presented in schematic drawings of earlier studies [18,20,22-24,28]. 

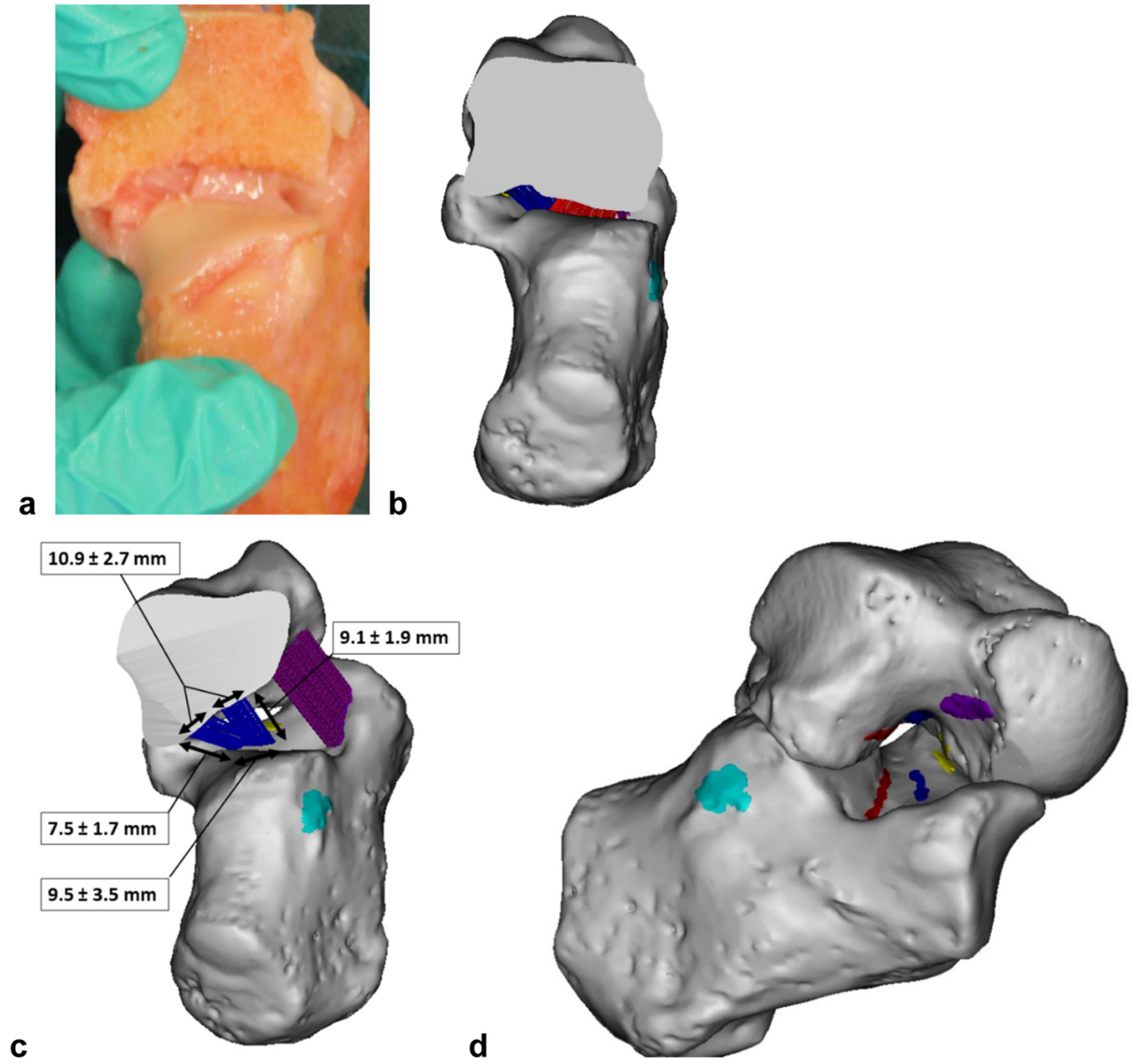

Fig. 3. The interosseous talocalcaneal ligament.

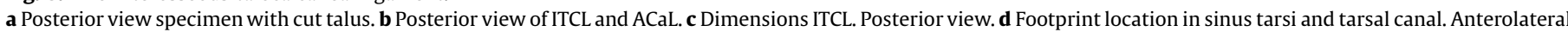
view.

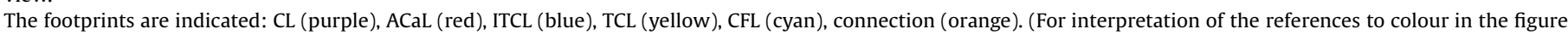
legend, the reader is referred to the web version of this article.)

The footprint of the $\mathrm{CL}$ is almost parallel to the axis of the calcaneus, all fibers get tensioned when applying inversion stress. The larger dimensions of the CL and the location more distant from the axis of rotation, compared to the ITCL, suggest a more important function of this ligament in the stability of the subtalar joint. Consequently, this raises some questions about biomechanical studies assessing serial cuttings of the subtalar ligaments, but omitting the CL from the protocol [29-31].

Although many authors consider the ITCL to be a strong ligament that contributes substantially to the stability of the subtalar joint, it is not clear if the described ligaments corresponded to the "real" ITCL [15]. Our study demonstrates the ITCL to be smaller than was previously supposed. The footprints of the ITCL are located medially in the sinus tarsi near the axis of movement. This suggests a more limited function in resisting inversion stress.

The ACaL was first described as a thickened segment of the anterior capsule of the posterior talocalcaneal joint [17]. Stephens and Sammarco considered the ACaL to play a major role in subtalar stability in all positions [24]. Two recent MRI studies that found a correlation between an ACaL injury and STI [14,32]. As the lateral fibers get tensioned during inversion stress and all fibers get tensioned during anterior drawer, it can explain the images of injury related to subtalar instability $[14,32]$. However, as the dimensions are rather small, it is still questionable if an injury of this ligament is rather a sign than a cause of subtalar instability.

Although our study confirms a clear distinction between the ACaL and ITCL, the ACaL is sometimes indicated as the ITCL $[18,19]$. The ACaL is more laterally located and easier to visualise. Frey et al. used subtalar arthroscopy and found ITCL tears in patients with sinus tarsi syndrome [18]. As the ITCL is located on the medial site in the tarsal canal in contrast to the more superficial located ACaL in the sinus tarsi, they probably described ACaL lesions. In earlier biomechanical studies, performing sections of the ITCL, anatomical or technical descriptions are insufficient to indicate the sectioned ligament $[8,10,25,30]$.

The anatomical findings in the current study have some clinical implications. 

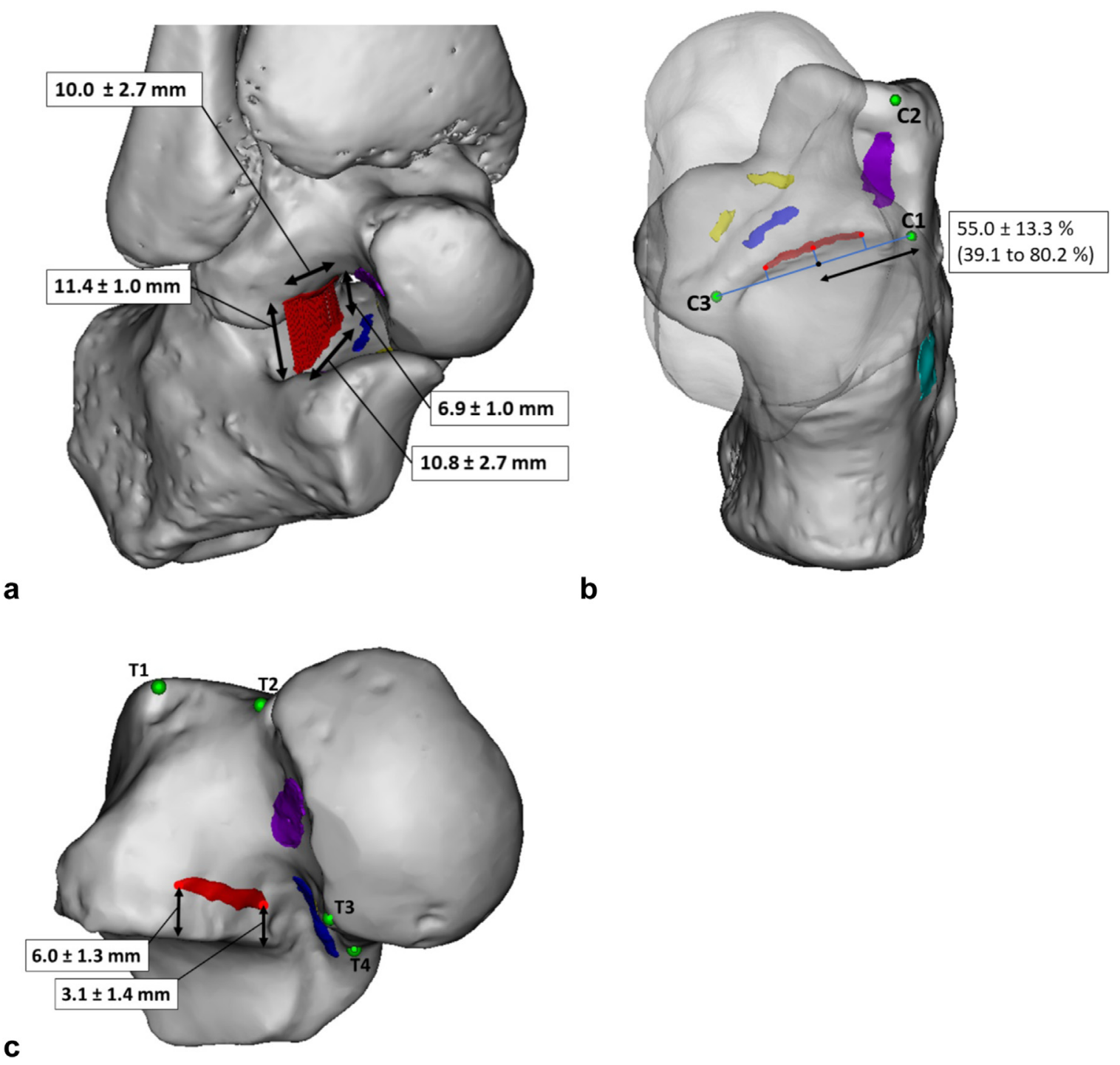

Fig. 4. The anterior capsular ligament. a Dimensions ACaL. b Footprint location on calcaneus. Superior view. $\mathbf{c}$ Footprint location on talus. Anteroinferior view. The different osseous landmarks and footprints indicated on talus and calcaneus. The footprints are indicated: CL (purple), ACaL (red), ITCL (blue), TCL (yellow). The line connecting landmark $\mathrm{C} 1$ and $\mathrm{C} 2$ was used as a reference to assess the $\mathrm{ACaL}$ calcaneal footprint in the coronal plane. (For interpretation of the references to colour in the figure legend, the reader is referred to the web version of this article.)

Table 3

Terminology used to indicate the subtalar ligaments.

\begin{tabular}{ll}
\hline Most commenly used term & Other terms \\
\hline Cervical ligament [35] & - Ligament of Fick [36] \\
& - Anterolateral talocalcaneal ligament [37] \\
& - Anterior talocalcaneal ligament [38] \\
& - Lig talocalcaneum obliquum [23] \\
& - Laternal talocalcaneal ligament [39] \\
& - Cervical talo-calcaneal ligament [28] \\
& - "Hedge" ligament of Farabeuf \\
& - Ligament of the tarsal canal [36] \\
& - Oblique astragalo-calcanean ligament [39] \\
& - Cruciate ligament of the tarsus [36] \\
- Axial ligament [36] & - Posterior capsular ligament [15] \\
Interosseous talocalcaneal ligament & - Ligament of the anterior capsule of the posterior talocalcaneal joint [24] \\
& - Anterior talocalcaneal ligament [20] \\
& - Anterior part of the interosseous ligament [36] \\
Anterior capsular ligament & Reinforcement of the subtalar anterior joint's capsule [36] \\
\hline Tarsal canal ligament [15] &
\end{tabular}

Please cite this article in press as: F. Michels, et al., The intrinsic subtalar ligaments have a consistent presence, location and morphology, Foot Ankle Surg (2020), https://doi.org/10.1016/j.fas.2020.03.002 
Table 4

Overview of studies assessing the dimensions of ITCL, CL and ACaL. Mean values $(\mathrm{mm})$.

\begin{tabular}{|c|c|c|c|c|}
\hline Study & No of specimens & ITCL & $\mathrm{CL}$ & ACaL \\
\hline Cahill [21] & 5 embalmed & $\begin{array}{l}\text { - Length: } 15 \\
\text { - Width: } 5.6 \\
\text { - Thickness: } 1.6\end{array}$ & $\begin{array}{l}\text { - Length: } 19.6 \\
\text { - Width: } 11.6 \\
\text { - Thickness: } 2.8\end{array}$ & NR \\
\hline Jotoku et al. [12] & 40 embalmed & $\begin{array}{l}\text { Bandtype } \\
\text { - Length: } 10.0 \pm 3.5 \\
\text { - Width: } 8.5 \pm 2.7 \\
\text { - Thickness: } 2.3 \pm 0.7 \\
\text { Fantype } \\
\text { - Length: } 7.5 \pm 2.1 \\
\text { - Width: } 11.0 \pm 1.3 \\
\text { - Thickness: } 3.0 \\
\text { Multiple type } \\
\text { - Length: } 7.0 \\
\text { - Width: } 8.5 \\
\text { - Thickness: } 3.0 \pm 0\end{array}$ & NR & $\begin{array}{l}\text { - Length: } 8.3 \pm 1.6 \\
\text { - Width: } 8.3 \pm 1.7 \\
\text { - Thickness: } 1.4 \pm 0.4\end{array}$ \\
\hline Li et al. [15] & 32 fresh-frozen & $\begin{array}{l}\text { - Length: } 10.6 \pm 1.2 \\
\text { - Width: } 7.5 \pm 1.2 \\
\text { - Thickness: } 1.5 \pm 0.2\end{array}$ & $\begin{array}{l}\text { - Length: } 13.3 \pm 1.9 \\
\text { - Width: } 9.5 \pm 1.6 \\
\text { - Thickness: } 2.6 \pm 0.5\end{array}$ & $\begin{array}{l}\text { - Length: } 13.6 \pm 2.0 \\
\text { - Width: } 10.1 \pm 1.4 \\
\text { - Thickness: } 2.4 \pm 0.3\end{array}$ \\
\hline Clanton et al. [41] & 14 fresh-frozen & NR & Length: 15.2 & NR \\
\hline Poonja et al. [16] & 26 formalin-fixed & NR & $\begin{array}{l}\text { Anterior } \\
\text { - Length: } 8.27 \pm 2.52 \\
\text { Superior: } 0.62 \pm 0.24 \\
\text { Inferior: } 0.70 \pm 0.26 \\
\text { Posterior } \\
\text { - Length: } 13.95 \pm 5.96 \\
\text { Superior: } 1.05 \pm 0.30 \\
\text { Inferior: } 1.20 \pm 0.34 \\
\text { - Width: } 9.15 \pm 2.45\end{array}$ & NR \\
\hline Yamaguchi et al. [42] & 21 embalmed & $\begin{array}{l}\text { Footprint calcaneum included } \\
\text { medial root IER } \\
\text { - Width: } 16.8 \pm 1.8\end{array}$ & $\begin{array}{l}\text { Footprint calcaneum } \\
\text { - Width: } 7.2 \pm 2.3 \\
\text { - Length: } 10.8 \pm 2.7\end{array}$ & NR \\
\hline This study & 16 fresh-frozen & $\begin{array}{l}\text { - Length lateral: } 9.1 \pm 1.9 \\
\text { - Length medial: } 7.5 \pm 1.7 \\
\text { - Talar width: } 13.3 \pm 4.7 \\
\text { - Calcaneal width: } 10.1 \pm 2.3 \\
\text { - Thickness: } 1.1 \pm 0.9\end{array}$ & $\begin{array}{l}\text { - Length anterior: } 13.9 \pm 1.5 \\
\text { - Length posterior: } 18.5 \pm 2.9 \\
\text { - Talar width: } 13.6 \pm 2.2 \\
\text { - Calcaneal width: } 15.8 \pm 3.7 \\
\text { - Thickness: } 1.7 \pm 0.7\end{array}$ & $\begin{array}{l}\text { - Length lateral: } 11.4 \pm 1.0 \\
\text { - Length medial: } 6.9 \pm 1.0 \\
\text { - Talar width: } 10.1 \pm 2.0 \\
\text { - Calcaneal width: } 12.1 \pm 2.4\end{array}$ \\
\hline
\end{tabular}

NR: not reported, IER: inferior extensor retinaculum.

First, this study quantifies the anatomical characteristics of the different subtalar ligaments, which may aid to infer their function and biomechanical properties. The current findings suggest an important function of the ACaL and certainly the $\mathrm{CL}$ in resisting inversion stress and anterior drawer. Because the ITCL is a small, medially located structure, it probably has a limited function to maintain to resist inversion stress.

Second, the findings in this study may be helpful for improving diagnostic tools. As MRI is valuable to assess the ligamentous structures, the more detailed information of these ligaments can be used to recognise the structures and to interpret possible lesions. Special attention should be paid to the ACaL and CL in patients with a suspicion of subtalar instability. Because most footprints are parallel to the tarsal canal, MRI views in planes corresponding the tarsal canal may be most informative.

Besides MRI, peroperative evaluation of the ligaments is seen as an important diagnostic step before ligament reconstruction [7,33]. The information in this study may be useful to perform this evaluation. The more laterally localized ACaL is easily found even with an endoscopic technique. An abnormal aspect of the ACaL may be a sign of subtalar instability. The CL is difficult to visualise and needs resection of the lateral root of the IER. This should be considered in patients with a suspicion of subtalar instability. As the ITCL is deeply located in the tarsal canal, it is very difficult to see with a lateral approach.

Third, the findings in this study about the location of the footprints can be helpful when a reconstruction of particular intrinsic ligaments is considered. The reconstructed ligament needs to have a similar dimension and location as the ligament to be replaced. Tourne et al. found lesions of the CL and ITCL in $30 \%$ of 150 patients selected for a surgical stabilisation procedure [34]. It is still unclear if reconstruction of the CFL in addition to a ATFL is insufficient in certain cases with subtalar instability [7].

This study has some limitations. A first limitation is that the measurements were obtained from cadaver specimens of advanced age. We know that ageing can affect ligament integrity and this should be taken into account when looking at the results.

In addition, we did not assess the different roots of the IER because of methodological constraints. As the approach to the structures in the tarsal canal is rather difficult, priorities in this study have been set on the assessment of the ligaments.

Inter- and intra-observer reliability were not calculated since the least accurate step, outlining and painting the ligament insertions by hand, could only be performed once.

\section{Conclusion}

This study identified a consistent presence, location, morphology and dimensions of the intrinsic subtalar ligaments which clarifies the confusion about terminology and location. These findings suggest a more important role of the $\mathrm{CL}$ and ACaL in the stability of the subtalar joint. This information is helpful to improve biomechanical studies. The detailed anatomical information of the subtalar ligaments, is also useful to improve diagnostic techniques as MRI and peroperative evaluation. Information about location and dimension is also needed when a reconstruction of those particular ligaments is performed. 


\section{Funding}

This research did not receive any specific grant from funding agencies in the public, commercial, or not-for-profit sectors.

\section{Conflict of interest}

None of the authors has a conflict of interest that could inappropriately influence this work.

\section{Acknowledgments}

We thank Marie Vanhoof and Elise Lesage from the Jan Palfijn Anatomy Lab of the Kulak (KU Leuven) for their support with specimens and infrastructure. We thank the radiologic Department of AZ Groeninge, Kortrijk, Belgium, for the support with the CT scan imaging

\section{References}

[1] Usuelli FG, Mason L, Grassi M, Maccario C, Ballal M, Molloy A. Lateral ankle and hindfoot instability: a new clinical based classification. Foot Ankle Surg 2014;20(4):231-6.

[2] Michels F, Pereira H, Calder J, Matricali G, Glazebrook M, Guillo S, et al. Searching for consensus in the approach to patients with chronic lateral ankle instability: ask the expert. Knee Surg Sports Traumatol Arthrosc 2018;26:2095-102.

[3] Matsui K, Takao M, Tochigi Y, Ozeki S, Glazebrook M. Anatomy of anterior talofibular ligament and calcaneofibular ligament for minimally invasive surgery: a systematic review. Knee Surg Sports Traumatol Arthrosc 2017;25 (6):1892-902.

[4] Michels F, Cordier G, Guillo S, Stockmans F, ESKKA-AFAS ankle instability group. Endoscopic ankle lateral ligament graft anatomic reconstruction. Foot Ankle Clin 2016;21:665-80.

[5] Barg A, Tochigi Y, Amendola A, Phisitkul P, Hintermann B, Saltzman CL. Subtalar instability: diagnosis and treatment. Foot Ankle Int 2012;33(2):151-60.

[6] Krähenbühl N, Weinberg MW, Davidson NP, Mills MK, Hintermann B, Saltzman $\mathrm{CL}$, et al. Currently used imaging options cannot accurately predict subtala joint instability. Knee Surg Sports Traumatol Arthrosc 2019;27:2818-30, doi: http://dx.doi.org/10.1007/s00167-018-5232-8.

[7] Michels F, Clockaerts S, Van Der Bauwhede J, Stockmans F, Matricali G. Does subtalar instability really exist? A systematic review. Journal Foot Ankle Surg 2020;26:119-27, doi:http://dx.doi.org/10.1016/j.fas.2019.02.001.

[8] Ringleb SI, Dhakal A, Anderson CD, Bawab S, Paranjape R. Effects of lateral ligament sectioning on the stability of the ankle and subtalar joint. J Orthop Res 2011;29(10):1459-64, doi:http://dx.doi.org/10.1002/jor.21407.

[9] Tochigi Y, Amendola A, Rudert MJ, Baer TE, Brown TD, Hillis SL, et al. The role of the interosseous talocalcaneal ligament in subtalar joint stability. Foot Ankle Int 2004:25:588-96.

[10] Kjaersgaard-Andersen P, Wethelund JO, Nielsen S. Lateral talocalcanea instability following section of the calcaneofibular ligament: a kinesiologic study. Foot Ankle Int 1987:7:355-61.

[11] Li L, Gollhofer A, Lohrer H, Dorn-Lange N, Bonsignore G, Gehring D. Function of ankle ligaments for subtalar and talocrural joint stability during an inversion movement - an in vitro study. J Foot Ankle Res 2019;12:16, doi:http://dx.doi. org/10.1186/s13047-019-0330-5.

[12] Jotoku T, Kinoshita M, Okuda R, Abe M. Anatomy of ligamentous structures in the tarsal sinus and canal. Foot Ankle Int 2006;27(7):533-8.

[13] Kelikian A. Sarafian's anatomy of the foot and ankle: descriptive topographical, functional. 3rd ed. Philadelphia: Lippincott Williams \& Wilkins; 2011.

[14] Kim TH, Moon SG, Jung HG, Kim NR. Subtalar instability: imaging features of subtalar ligaments on 3D isotropic ankle MRI. BMC Musculoskelet Disord 2017;18(1):475, doi:http://dx.doi.org/10.1186/s12891-017-1841-5.
[15] Li SY, Hou ZD, Zhang P, Li HL, Ding ZH, Liu YJ. Ligament structures in the tarsal sinus and canal. Foot Ankle Int 2013;34(12):1729-36.

[16] Poonja AJ, Hirano M, Khakimov D, Ojumah N, Tubbs RS, Loukas M, et al. Anatomical study of the cervical and interosseous talocalcaneal ligaments of the foot with surgical relevance. Cureus 2017;9(6):e1382, doi:http://dx.doi. org/10.7759/cureus.1382.

[17] Sarrafian SK. Anatomy of the foot and ankle. Descriptive, topographic, functional. 2nd ed. Philadelphia: J.B. Lippincott Companie; 1993.

[18] Frey C, Feder KS, DiGiovanni C. Arthroscopic evaluation of the subtalar joint: does sinus tarsi syndrome exist? Foot Ankle Int 1999;20(3):185-91.

[19] Golanó P, Vega J, de Leeuw P, Malagelada F, Manzanares MC, Götzens V, et al. Anatomy of the ankle ligaments: a pictorial essay. Knee Surg Sports Traumatol Arthrosc 2010;18(5):557-69.

[20] Bartoníček J, Rammelt S, Naňka O. Anatomy of the subtalar joint. Foot Ankle Clin 2018;23(3):315-40.

[21] Cahill DR. The anatomy and function of the contents of the human tarsal sinus and canal. Anat Rec 1965;153:1-18.

[22] Harper MC. The lateral ligamentous support of the subtalar joint. Foot Ankle $1991 ; 11(6): 354-8$.

[23] Schmidt HM. Gestalt und Befestigung der Bansysteme im Sinus und Canalis tarsi des Menschen. Acta Anat 1978;102:184-94.

[24] Stephens MM, Sammarco GJ. The stabilizing role of the lateral ligament complex around the ankle and subtalar joints. Foot Ankle 1992;13(3):130-6.

[25] Knudson GA, Kitaoka HB, Lu CL, Luo ZP, An KN. Subtalar joint stability. Talocalcaneal interosseous ligament function studied in cadaver specimens. Acta Orthop Scand 1997;68(5):442-6.

[26] Kato T. The diagnosis and treatment of instability of the subtalar joint. J Bone Joint Surg Br 1995;77:400-6.

[27] Meyer JM, Garcia J, Hoffmeyer P, Fritschy D. The subtalar sprain. A roentgenographic study. Clin Orthop Relat Res 1988;226:169-73.

[28] Mabit C, Boncoeur-Martel MP, Chaudruc JM, Valleix D, Descottes B, Caix M. Anatomic and MRI study of the subtalar ligamentous support. Surg Radiol Anat 1997;19(2):111-7.

[29] Heilman AE, Braly WG, Bishop JO, Noble PC, Tullos HS. An anatomic study of subtalar instability. Foot Ankle 1990;10(4):224-8.

[30] Ishii T, Miyagawa S, Fukubayashi T, Hayashi K. Subtalar stress radiography using forced dorsiflexion and supination. J Bone Joint Surg Br 1996;78(1):5660.

[31] Weindel S, Schmidt R, Rammelt S, Claes L, v Campe A, Rein S, Subtalar instability: a biomechanical cadaver study. Arch Orthop Trauma Surg 2010;130 (3):313-9.

[32] Yoon DY, Moon SG, Jung HG, Kim NR. Differences between subtalar instability and lateral ankle instability focusing on subtalar ligaments based on three dimensional isotropic magnetic resonance imaging. J Comput Assist Tomogr 2018;42:566-73, doi:http://dx.doi.org/10.1097/RCT.0000000000000717.

[33] Mittlmeier T, Rammelt S. Update on subtalar joint instability. Foot Ankle Clin 2018;23(3):397-413.

[34] Tourné Y, Mabit C, Moroney PJ, Chaussard C, Saragaglia D. Long-term follow-up of lateral reconstruction with extensor retinaculum flap for chronic ankle instability. Foot Ankle Int 2012;33(12):1079-86.

[35] Wood Jones F. The talocalcanean articulation. Lancet 1944;247:241-2.

[36] Viladot A, Lorenzo JC, Salazar J, Rodríguez A. The subtalar joint: embryology and morphology. Foot Ankle 1984;5:54-66.

[37] Shellshear JL. Macintosh NWG surveys of anatomical fields. Sydney: Grahame; 1949. p. $156-72$

[38] Testut L, Latarjet A. Tratado de anatomia humana (A treatise on human anatomy). Barcelona: Salvat Editores, SA; 1985. p. 704-19.

[39] Smith B. The astragalo-calcaneo-navilar joint. J Anat Phys 1896;30:390-412.

[40] Last RJ. Specimens from the hunterian collection. J Bone Joint Surg Br 1952;34$\mathrm{B}(1): 116-9$.

[41] Clanton TO, Campbell KJ, Wilson KJ, Michalski MP, Goldsmith MT, Wijdicks CA, et al. Qualitative and quantitative anatomic investigation of the lateral ankle ligaments for surgical reconstruction procedures. J Bone Joint Surg Am 2014:96(12):e98.

[42] Yamaguchi R, Nimura A, Amaha K, Yamaguchi K, Segawa Y, Okawa A, et al. Anatomy of the tarsal canal and sinus in relation to the subtalar joint capsule. Foot Ankle Int 2018;27:1071100718788038, doi:http://dx.doi.org/10.1177/ 1071100718788038 . 